\title{
Karpal tünel sendromu ve median sinirin diğer tuzak nöropatileri
}

\section{Carpal tunnel syndrome and other entrapment neuropathies of the median nerve}

\author{
Mustafa Kürklü, Selim Türkkan, Harun Yasin Tüzün \\ GATA, El ve Üst Ekstremite Cerrahisi Bilim Dalı, Ankara
}

\begin{abstract}
Median sinir başta karpal tünel içerisinde olmak üzere üst ekstremitenin çeşitli seviyelerinde tuzaklanabilir. Tuzaklanma bulguları tuzaklanma seviyesine göre değişirken genelde başparmak, ikinci, üçüncü ve dördüncü parmağın lateral yarısında ağı, his kaybı, karıncalanma, elde güçsüzlük şeklinde görülür. Tanıda Phalen testi, Tinel bulgusu, Durkan testi, Semmes-Weinstein monofilaman testleri, el diyagram skorlaması gibi fizik muayene testlerinden yararlanılabilir. Ayrıca tanı koymada görüntüleme araçlarından ve elektorizyolojik çalışmalardan faydalanılır. Konservatif tedavide gece ateli, steroid enjeksiyonu, NSAID lerden faydalanılabilmektedir. İlerlemiş olgularda veya konsevatif tedaviden fayda görmeyen hastalarda cerrahi tedaviler yapılmaktadır. Cerrahi tedavilerde açık cerrahi, mini açık cerrahi ve endoskopik cerrahi başarılı bir şekilde uygulanabilmektedir. Bu cerrahi tekniklerin birbirlerine üstünlüğünü kesin olarak gösteren çalışmalar yok denecek kadar azdır. Fakat endoskopik cerrahinin öğrenme eğrisi uzun olması nedeni ile bu cerrahiyi uygulamada deneyim çok önemlidir.

Anahtar sözcükler: karpal tünel sendromu; median sinir; tuzak nöropatiler
\end{abstract}

Median nerve. can be trapped anywhere especially in the carpal canal during the course of the upper limbs. Although sign and symptoms of the trapment can be changed according to entrapment level, generally symptoms are seen in thumb, second, third and lateral half of the fourth finger as pain, paresthesia, tingling, numbness and hand weakness. We can use physical examination tests such as Phalen test, Durcan test, Tinel test, Semmes-Weinstein sensibility test and hand diagram test. Furthermore we can also use imagining tools and electrodiagnostic studies to make diagnosis. The night splint, steroid injection and NSAID can be used as conservative treatment. The mini open surgery, open surgery and endoscopic surgery can be performed successfully as surgical treatment modalities. The studies showing precisely the superiority of these surgical techniques to each others are very low. The endoscopic surgery technique has long learning curve and thus more experience is needed.

Key words: carpal tunnel syndrome; median nerve; entrapment neuropathies
K arpal tünel sendromunu, ilk olarak Paget 1854 yılında tanımlamış olup, klinik seyri ile ilgili detaylı bilgi ve cerrahi teknikler Phalen tarafindan yapılmıştır. Karpal tünel sendromu (KTS), median sinirin el bileği seviyesinde basıya uğraması olarak tanımlanır ve üst ekstremitenin en sık karşılaşılan tuzak nöropatisidir. ${ }^{[1-3]}$

\section{EPIDEMIYOLOJi}

KTS sıklıkla 3.-5. onyıllar arasında görülür. Kadın/ erkek oranı 3/1 olarak saptanmıştır. İnsidans, erkeklerde yaşla birlikte artarken, kadınlarda menopozla birlikte hızlı bir artış gösterir; kadınlarda 100.000'de
149, erkeklerde 100.000 'de 52'dir. Prevalans ise, kadınlarda \%3-3,4'ken erkeklerde \%0,6-2,7 olarak gösterilmiştir. ${ }^{[4,5]}$

\section{ANATOMI}

KTS'yi diğer median nöropatilerden, kök basılarından ve brakiyal pleksus lezyonlarından ayırt edebilmek için, median sinir ve karpal tünel (KT) anatomisinin bilinmesi gerekir.

KT'nin lateralinde skafoid ve trapezium, mediyalinde hamat ve pisiform kemikler bulunmakta olup, bu yapının oluşturduğu arkın tabanını tranvers karpal bağ

- Iletişim adresi: Dr. Harun Yasin Tüzün, GATA, El ve Üst Ekstremite Cerrahisi Bilim Dalı, 06010 Etlik, Ankara

Tel: 0312 - 3045515 e-posta: tuzundr@yahoo.com

- Geliș tarihi: 13 Ekim $2015 \quad$ Kabul tarihi: 13 Ekim 2015 


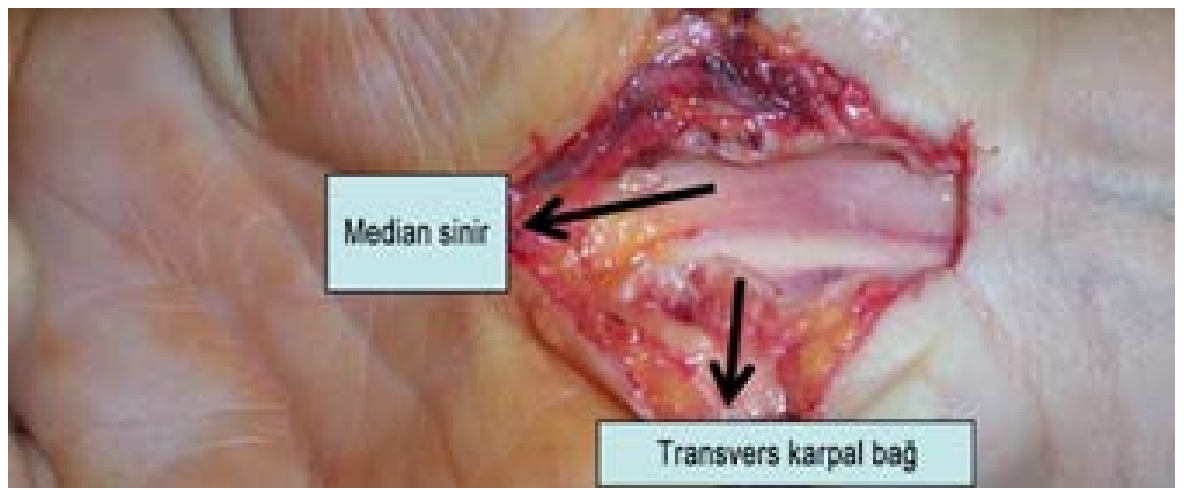

Şekil 1. Transvers karpal bağ serbestleştirilmesi sonrası, median sinirin görünümü.

örtmektedir. ${ }^{[1-3]}$ Fleksör retinakulum ise transvers karpal bağın üstünü örtmektedir. Bu yapının içerisinden dört adet derin fleksör, dört adet yüzeyel fleksör, fleksör pollisis longus (FPL) ve median sinir geçmektedir; median sinir KT'nin en volarinde olan yapıdır (Şekil 1). Median sinir, brakiyal pleksusun mediyal ve lateral kordlarının birleşmesi sonucu oluşur. Lateral kord, C6-C7 köklerinden dal alır; tenar bölgenin, baş, orta ve işaret parmağın duyusal innervasyonunu, proksimal önkol median kaslarının büyük kısmının motor innervasyonunu sağlar. Mediyal kord ise C8-T1 köklerinden dal alır; distal önkol ve eldeki median kasların büyük kısmının motor innervasyonunu, ayrıca yüzük parmağının lateral yarısının duyusal innervasyonunu sağlar. Motor dal, distale avuç içine doğru ilerler; 1. ve 2 . lumbrikal kasları innerve eder. Ayrıca, tenar bölge kaslarının bir çoğunu, opponens pollisis, abduktor pollisis brevis, fleksör pollisis brevisin yüzeyel başını innerve eden rekürren tenar motor dalı verir. KT'den geçen median sinir duyu dalı ise, başparmak mediyalinin, işaret parmağı, orta parmak ve yüzük parmağın lateral kısmının duyusunu alır. Median sinirin, el bileği seviyesinde üç ana yapısı vardır. Birinci yapı, median sinirin palmar kutanöz dalıdır. Bu dal, transvers karpal bağdan önce median sinirden ayrilır ve elin tenar bölgesini innerve eder. Palmar kutanöz dalın varyasyonları vardır. İkinci yapı, median sinirin rekürren motor dalıdır. Bu dal da, birçok varyasyonlarla median sinirden ayrılır. En sık karşılaşılan, ekstraligamentöz olarak ayrılmış şeklidir. En son yap olan ana median sinir ise, lateral ve mediyal trunkuslara ayrılır ve birinci, ikinci, üçüncü parmakların ve dördüncü parmağın volar, radyal kısmının duyusunu alan dijital sinirleri oluşturur. ${ }^{[1-3,5]}$

\section{KLINIK}

KTS oluşumunda birçok etiyolojik neden vardır. Bunlar altı ana gruba ayrılır: birincisi KT'nin hacmini azaltan etiyolojik nedenler; ikincisi kanal içi yapıların hacminin artması veya kanal içi ekstra yapıların varlığı; üçüncüsü nöropatik değişiklikler; dördüncüsü inflamatuvar nedenler (tendonların sinoviti vb.); beşincisi sıvı dengesindeki değişmelerle seyreden klinik durumlar; altıncısı ise eksternal basılardır. İdiyopatik KTS' de en sık etiyolojik neden, kanal içindeki tendonların sinovitidir. ${ }^{[1,5,6]}$

Hamilelikte görülen KTS, doğum sonrası geriler. Çocuklarda KTS, çok nadir olarak görülür ve bazı genetik hastalıklara eşlik eder. KTS'de tünel içi basıncın artması, epinöral dolaşımı engelleyip sinirin fonksiyonunda bozulmaya neden olmaktadır. ${ }^{[1-5]}$ KTS'de hastalar karşımıza, median sinirin innerve ettiği başparmak, işaret parmak, orta parmak ve yüzük parmağın radyal kısmında karıncalanma, uyuşma, ağrı, acı ve zonklama şikayetleri ile gelir. Daha ağır olgularda ise, abduktor pollisis brevis, opponens pollisis kaslarında atrofi ve güçsüzlük meydana gelir; fizik muayenede, tenar bölgede atrofi gözlemlenir. ${ }^{[1-5,7]}$

\section{TANI}

Tanı için, hastanın hikayesi, özel fizik muayene testleri ve elektrofizyolojik çalışmalardan yararlanılır. KTS'de hastalar karşımıza, median sinirin innerve ettiği birinci, ikinci, üçüncü parmaklarda ve dördüncü parmağın radyal tarafında karıncalanma, uyuşma, ağrı, acı ve gece uykudan uyandıran ağrı şikayetleri ile gelir. Hastaların şikayetleri, ellerini havaya kaldırma, direksiyon kullanma, kulağa telefon tutma gibi aktivitelerle artar. ${ }^{[1-7]}$ Hastalar ağrılarını, el egzersizleri yaparak ve ellerini sallayarak geçirmeye çalışırlar. Bu hareketler, hastalığın başında semptomların azalmasında yararlıyken, ileri evrelerde rahatlama sağlayamamaktadır. Ileri evrelerdeki hastalarda, el becerilerinde azalma, düğme iliklemede zorluk ve küçük nesneleri kavramada güçlük gibi şikayetler görülür. ${ }^{[1-5,7]}$ 


\section{Fizik Muayene Testleri}

KTS'nin klinik tanısında provokatif testlerin önemi büyüktür. Bu testler:

Tinel belirtisi; el bileği seviyesinde median sinirin bulunduğu lokalizasyona, transvers karpal bağın üzerinden perküsyon yaparak median sinirin innerve ettiği alanda uyuşukluk, karıncalanma gibi şikayetlerin oluşması ile pozitif olur. Tinel testi, \%60 duyarlılık ve \%67 özgüllüğe sahiptir. ${ }^{[1-3,6,8,9]}$

Phalen testinde; her iki el bileği birbirine yaklaştırılarak $90^{\circ}$ fleksiyona getirilir ve bu pozisyonda hastadan 60 sn beklemesi istenir. Bu süre sonunda, median sinir duyu alanında uyuşukluk ve karıncalanma gibi belirtilerin gözlenmesi, testin pozitif olduğu anlamına gelir. Ancak, Phalen testi, Tinel testine göre daha az hastada pozitiftir. Phalen testi \%75 duyarlılık ve \%47 özgüllüğe sahiptir. ${ }^{[1-3,5,9,10]}$

Durkan testi; diğer bir provokatif test olup, hekimin her iki başparmağını üst üste koyarak hastanın tranvers karpal bağ üzerine 30 sn basınç uygulaması şeklinde yapilır. Bu provokasyon sonucunda semptomların oluşması, testin pozitif olduğunu gösterir. Durkan testinde özgüllük oranı \%90, duyarlılıkoranı ise $\% 87$ 'dir. ${ }^{[1-3,6]}$

Diğer bir testte ise, üst ekstremiteye tansiyon manşonu ile, tansiyon ölçer gibi basınç uygulaması yapılır; basınç ile oluşan venöz göllenme, bu hastalarda KTS belirtilerini oluşturur. ${ }^{[1-3]}$

Gellman ve arkadaşları, KTS'li hastalarda yaptıkları çalışmada KT basıncını, el bileği nötral pozisyondayken $32 \mathrm{mmHg}, 90^{\circ}$ fleksiyondayken $99 \mathrm{mmHg}, 90^{\circ}$ ekstansiyonda ise $110 \mathrm{mmHg}$ olarak bulmuşlardır. Kontrol grubunda ise bu değerler, sırasıyla, 25, 31, 30 $\mathrm{mmHg}$ olarak bulunmuştur. ${ }^{[1-3,11]}$

Szabo ve arkadaşları, KTS'li hastalarda yaptıkları çalışmada, Phalen, Tinel, Durkan, Semmes-Weinstein monofilaman testleri, el diyagram skorlaması, gece ağrısı, kavrama gücü ve parmak sıkma güçlerini değerlendirmişlerdir; Phalen testini en duyarlı, el diyagram ve Tinel testini ise en özgül testler olarak bulmuşlardır. ${ }^{[3,8]}$

\section{TEDAVi}

Tedavi, hastalığın şiddetine göre şekillenir. Semptomların hafif ve kas atrofisinin olmadığı olgularda, konservatif tedavi olarak, KT'ye steroid enjeksiyonu (enjeksiyon yaparken unutulmaması gereken nokta, sinire direkt enjeksiyon yapılmamasıdır), non-steroid anti-inflamatuvar ilaçlar (NSAii) ve gece splinti uygulanır. Hastaların \%10'u bu tedaviden yarar görür. Başka bir çalışmada ise, KT içerisine enjeksiyon yapılan hastaların \%65-90'ında, 2-4 ay sonra semptomlarda rekürrens görüldüğü bildirilmiştir. ${ }^{[5,6,12,13]}$
Steroid enjeksiyonu, ayırıc tanı aracı olarak da kullanılmaktadır. Eğer etiyolojide, torasik outlet sendromu, servikal disk, karpal tünel içerisinde tümör veya kanal içi osteofit varlığı gibi başka bir neden rol oynuyorsa, enjeksiyon yarar sağlamayacaktır. Kaplan ve arkadaşları, stenozan fleksör tenosinovit varlığında, hastaların medikal tedaviden ne kadar yarar görecebileceğine dair bir çalışma yapmışlardır. Bu çalışmaya göre; yaşın 50'den fazla olması, 10 aydan fazla semptomların devam etmesi, 30 sn'den az sürede Phalen testinin pozitif hale gelmesi ve devamlı parastezi semptomlarından hiçbirinin olmadığı hastaların üçte ikisinin medikal tedaviden yarar sağladığı bildirilmiştir. ${ }^{[1-3,5,6]}$ Bahsedilen semptomlardan herhangi birinin varlığında, hastaların yaklaşık \%60'ı tedaviden yarar görmüş; bu semptomların dört veya beşinin varlı̆̆ında ise, hiçbiri medikal tedaviden yarar görmemiştir. ${ }^{[1-3,5,6]}$

Sonuç olarak; hafif ve başlangıç aşamasında medikal tedavi yararlı iken, ilerlemiş olgularda cerrrahi tedavi tercih edilen yöntemdir. Hastalığın etiyoloji ve derecesine göre tedavinin seçilmesi, daha doğru bir yaklaşım olarak belirtilmektedir. Bir Colles kırığında oluşan basıncın kaldırılması ve romatoid artrite bağlı KTS'de sinoviyektomi ile beraber serbestleştirme yapılması, kişiye yönelik tedavi örnekleri arasında sayılabilir. KT serbestleştirilmesinden altı ay sonra, tüm bulguların gerilediği ve hasta şikayetlerinin kaybolduğu görülmektedir. Tenar atrofinin ise, diğer semptomlara göre daha yavaş iyileştiği bilinmektedir. ${ }^{[1-3,5,6,12]}$

\section{CERRAHI TEDAVi}

Konservatif tedavinin yarar sağlamadığı ve ilk etapta konservatif tedavi düşünülmeyen ilerlemiş olgularda, cerrahi tedavi yapılmalıdır. Cerrahi tedavide amaç, transvers karpal bağı kesip karpal tüneli rahatlatmaktır. Operasyon, temel olarak üç şekilde gerçekleştirilmektedir. Bunlar; açık, mini açık ve endoskopik tekniktir (Şekil 2). ${ }^{[1-3,12,14-16]}$ Cerrahide en önemli husus, transvers karpal bağı tam serbestleştirmek ve sinir liflerine zarar vermemektir. Bunun için, cerrahi esnasında transvers karpal bağ, anatomik yapılar ve median sinir tam olarak görüldükten sonra kesilmelidir. ${ }^{[1-3,6]}$

Endoskopik teknikte amaç, yapılan kesi hattının kısalması ve kesiye bağlı ağrıları azaltmaktır. Fakat, zaman zaman görüş netliğinin sıkıntılı olması, median sinir motor dalı ile ilgili varyasyonları anlamadaki güçlük, iyatrojenik sinir hasarı oluşturma riski ve tam olmayan serbestleştirme, endoskopik KTS tedavisinin dezavantajları olarak sayılabilir. Bu dezavantajları ortadan kaldırmak için, esas cerrahiden önce, kadavrada çok sayıda serbestleştirmenin yapılması önerilmektedir. ${ }^{[1-3,6,15,16]}$ 


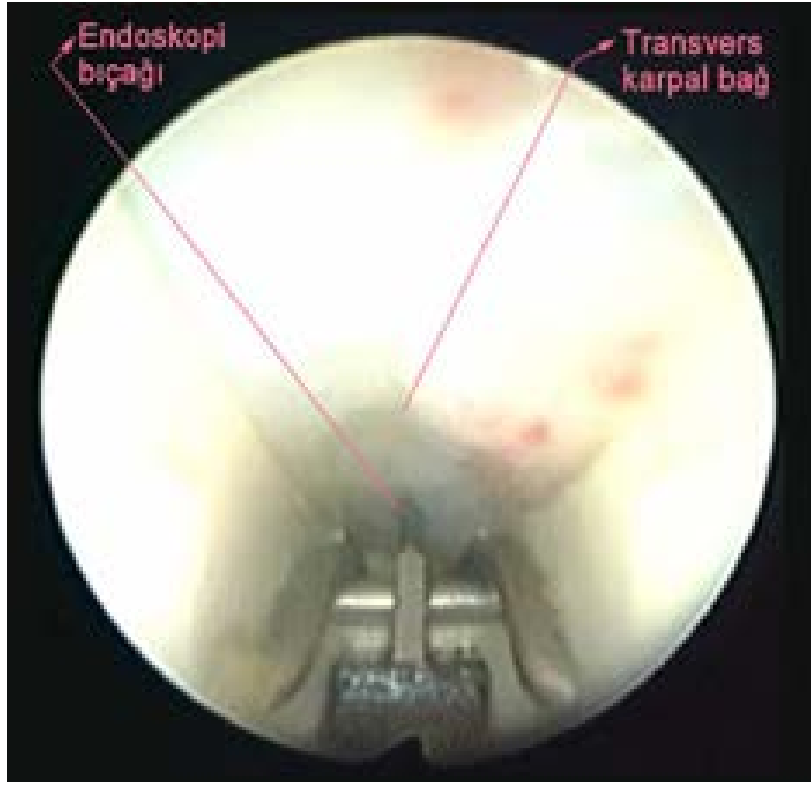

Şekil 2. Endoskopik olarak, transvers karpal bağın görünümü ve endoskopi bıçağının kesi hattı başlangıcına yerleştirilmesi.

Literatürde, açık, mini açık ve endoskopik cerrahilerden birinin diğerine göre kesin üstünlüğünü gösteren kapsamlı çalışmalara çok az rastlanmaktadır. ${ }^{[1-3,6,14-16]}$ Cerrahlar tarafından daha faza tercih edilen yöntemin ise, mini açık teknik olduğu görülmektedir. Literatürde, endoskopik ve açık teknikler arasında, cerrahiden üç ay sonra herhangi bir klinik farkın olmadığını gösteren çok sayıda çalışma mevcuttur. Ancak, endoskopik tekniğin kullanıldığı olgularda, cerrahi sonrası dönemde ağrının daha az ve işe dönüş süresinin daha kısa olduğunu bildiren çalışma sayısı da oldukça fazladır. Özetlemek gerekirse; endoskopik KTS cerrahisinde, öğrenme eğrisi uzun ve deneyim şarttır. Endoskopik cerrahi sırasında görüntünün iyi alınamaması gibi oluşabilecek en küçük problemde ve malzeme ile ilgili sorunlarda, derhal açık cerrahiye geçmek önerilmektedir. ${ }^{[1-3,5,6,14-16]}$ Ayrıca, rekürrens olgularında ve diyabetik hastalarda açık teknik önerilir. ${ }^{[1-3,5,6,14-16]}$

Ameliyat sonrası, hastaların iki gün süre ile el bileği hareketlerini kısıtlaması ve ağrı kontrolü için nötral pozisyonda üç hafta gece ateli kullanması önerilir. Hastalar, 6-8 hafta sonra tüm aktiviteler yönünden serbest bırakılmalıdır. ${ }^{[1-3,6,12]}$

\section{MEDIAN SINIRIN DIĞER TUZAK NÖROPATILERI}

\section{Anterior İnterosseöz Sinir Sıkışma Sendromu (Kiloh ve Nevin Sendromu)}

Anterior interosseöz sinir (AiS) sıkışma sendromu, üst ekstremitede görülen tuzak nöropatilerin $\% 1$ 'ini

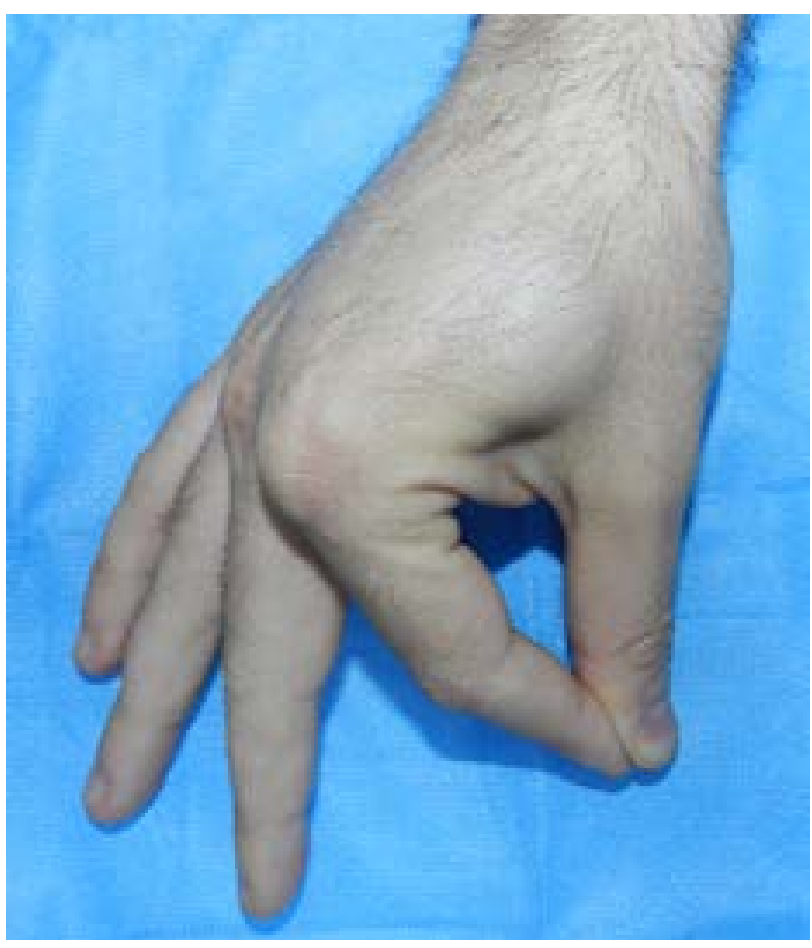

Şekil 3. OK (okey işareti) bulgusunun AiS tuzaklanmasındaki görünümü.

oluşturur. Kiloh ve Nevin, bu sendromu 1952 yılında tanımlamışlardır. Bu sinir, median sinirin majör bir dalı olup, mediyal epikondilin $6-8 \mathrm{~cm}$ distalinden ayrılır. $\mathrm{Bu}$ sinir, pronator teresin derin başı, diğer tendinöz varyasyonlar, fibröz bantlar ve kollateral damarlar tarafından tuzaklanabilmektedir. Ais sıkışma sendromu, travma sonucu oluşan kırıklar ve üst ekstremitedeki anatomik varyasyonlar nedeni ile oluşabileceği gibi, Parsonage-Turner sendromunda da (medulla spinalisin anterior boynuzunun nöriti) görülebilir. AiS, duyu lifi içermez ve FPL, 2. ve 3. parmak derin fleksörleri ile pronator kuadratus kaslarını innerve eder. Bu sinirin tuzaklanmasında, klinik olarak, birinci ve ikinci parmağın oppozisyon hareketinde oluşan çember şekli yapılamamaktadır (Şekil 3). Yine, bu sinir tuzaklanmasında da, önkolda Tinel bulgusu saptanabilir. Ayrıca, bu sinirin tuzaklanmasında, klasik KTS'de görülen, klasik lokalizasyonda olan ağrı ve parestezi gibi duyu kusurları saptanmaz. Hastalar, önkolda künt bir ağrıdan bahsedebilirler. Martin Gruber anastomozu bulunan olgularda, yani önkolda median ve ulnar sinir arasında anastomozu olan olgularda, farklı olarak, intrensek kaslarda etkilenme görülebilir. Tanı maksatlı sinir ileti çalışmaları kullanılabilir. Tedavide, 3-6 ay kadar izlem süresinden sonra iyileşmeyen olgularda, anterior interosseöz sinirin cerrahi olarak gevşetilmesi uygulanabilir. ${ }^{[1-4,6,17-21]}$ 


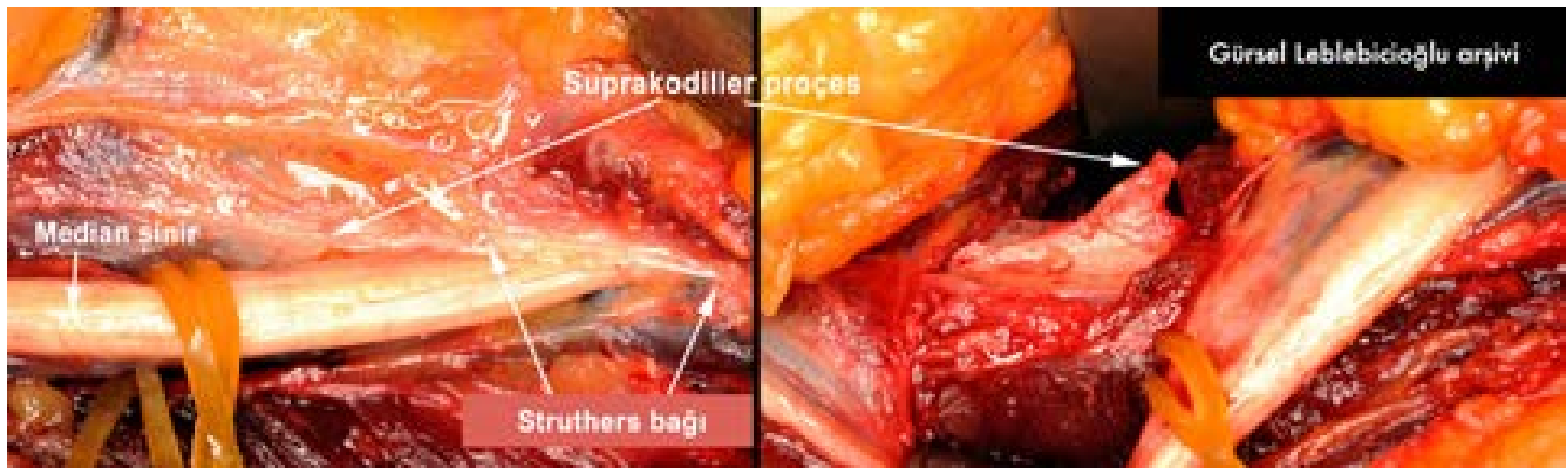

Şekil 4. Median sinir, suprakondiller proçes ve Struthers bağının anatomik ilişkisi.

\section{Suprakondiller Proses Sendromu}

Humerus'un distal anteromediyalinde bulunan gaga şeklindeki kemik yapı nedeniyle, median sinirin Struthers bağı altında sıkışması ile oluşan ve karpal tünel sendromu bulgularına benzer bulgulara yol açan nadir bir sendromdur (Şekil 4); Tiedemann ve Struthers tarafından tanımlanmıştır (bu yapı, 2-20 $\mathrm{mm}$ boyutlarında ve humerus mediyal epikondilinden yaklaşık $5 \mathrm{~cm}$ proksimalde bulunur). Sıklıkla unilateral olup, olguların çok az bir bölümünde bilateral görülür. Klinik olarak, humerus distalinde palpabl kitle, koldan ele doğru yayılan ağrı ve KTS bulguları saptanabilir. Bu sendromda, KTS'den farklı olarak, palmar kutanöz dalın etkilenmesine bağlı, palmar bölgede duyu kusuru bulunabilir. Ayrıca, radyografide humerus distalinde gaga şeklindeki kemik çıkıntının bulunması, ayıııcı tanıda önemlidir. Tanıda, direkt radyografi ile humerus distalindeki kemik çıkıntı, manyetik rezonans MR ve ultrasonografik görüntüleme ile de median sinirin tuzaklanması gösterilebilir. Yardımcı tanı yöntemi olarak, elektrodiyagnostik testler de kullanılabilir. Tedavide izlem ve semptomları gerilemeyen olgularda ise, kemik eksizyonu ve sinir serbestleştirilmesi cerrahi olarak yapılmaktadır. ${ }^{[1-3,6,17,22]}$

\section{Pronator Sendrom}

Bu patoloji, median sinirin, önkolda pronator teresin iki başı arasında, fleksör süperfisiyel arkta ve bisipital aponevrozda sıkışması ile oluşabilir. Pronator sendromda, median sinirin önkolda tuzaklanması sonucu, parmaklarda ve tenar eminenste izole duysal bozukluk görülür. Diğer el bilek seviyesi üzerinde olan median sinirin kompresif nöropatileri gibi, KTS'ye nazaran nadir görülür. Genellikle, üst ekstremitenin tekrarlayıcı sporları ile uğraşan kişilerde görülmektedir. Bu hastalarda, dirence karşı yapılan el bilek fleksiyonunda, pronasyonunda ve orta parmağın proksimal interfalengeal eklem fleksiyonunda semptomlar şiddetlenir. Yine, önkolda pronator teres kası üzerinde baskı oluşturulduğunda, median sinirin innerve ettiği alanda parastezi oluşur. Bu hastalarda, KTS'dekinin aksine, gece ağrıları olmaz. Elektrodiyagnostik testlerin tanı koymada etkinliği, yok denecek kadar azdır. Başlangıçta konservatif tedavi uygulanır. Konservatif tedavide immobilizasyon, NSAii, lokal steroid enjeksiyonu ve fizik tedavi uygulanabilir. Bu tedaviler ile semptomları gerilemeyen hastalara, cerrrahi serbestleştirme ameliyatları yapılabilir. ${ }^{[1-3,6,8,17,21-23]}$

\section{KAYNAKLAR}

1. Mackinnon SE, Novak CB. Compression Neuropathies. In: Wolfe SW, Hotchkiss RN, Pederson WC, Kozin HS, editors. Green's Operative Hand Surgery, 6th ed. Philadelphia: Churchill Livingstone Elsevier; 2011. p.985-94.

2. Beasley RW. Beasley's Surgery of the Hand, 1st ed. New York: Thieme Medical Publishers; 2003. p.443-55.

3. Canale ST, Beaty JH. Campbell's Operative Orthopaedics, 12th ed. Philadelphia, PA: Elsevier Mosby; 2012. p.3637-57.

4. Chammas M, Boretto J, Burmann LM, Ramos RM, Dos Santos Neto FC, Silva JB. Carpal tunnel syndrome - Part I (anatomy, physiology, etiology and diagnosis). Rev Bras Ortop 2014;49(5):429-36. CrossRef

5. Kaymak B, Özçakar L. Karpal Tünel Sendromu. Hacettepe Tip Dergisi 2007;38:141-6.

6. Spinner RJ, Amadio PC. Compressive neuropathies of the upper extremity. Clin Plast Surg 2003;30(2):155-73.

7. Serarslan Y, Melek iM, Duman T. Karpal Tünel Sendromu. Pamukkale Tıp Dergisi 2008;1:45-9.

8. Palumbo CF, Szabo RM. Examination of patients for carpal tunnel syndrome sensibility, provocative, and motor testing. Hand Clin 2002;18(2):269-77.

9. Gellman H, Gelberman RH, Tan AM, Botte MJ. Carpal tunnel syndrome. An evaluation of the provocative diagnostic tests. J Bone Joint Surg Am 1986;68(5):735-7.

10. Seror $\mathrm{P}$. Phalen's test in the diagnosis of carpal tunnel syndrome. J Hand Surg Br 1988;13(4):383-5. 
11. Gelberman RH, Hergenroeder PT, Hargens AR, Lundborg GN, Akeson WH. The carpal tunnel syndrome. A study of carpal canal pressures. J Bone Joint Surg Am 1981;63(3):380-3.

12. Chammas M, Boretto J, Burmann LM, Ramos RM, Neto FS, Silva JB. Carpal tunnel syndrome - Part II (treatment). Rev Bras Ortop 2014;49(5):437-45. CrossRef

13. Gelberman $\mathrm{RH}$, Aronson D, Weisman $\mathrm{MH}$. Carpal-tunnel syndrome. Results of a prospective trial of steroid injection and splinting. J Bone Joint Surg Am 1980;62(7):1181-4.

14. Szabo RM. Open carpal tunnel release is the preferred method of surgical treatment for carpal tunnel syndrome. J Bone Joint Surg Am 2002;84-A(8):1489.

15. Lee DH, Masear VR, Meyer RD, Stevens DM, Colgin S. Endoscopic carpal tunnel release: a cadaveric study. J Hand Surg Am 1992;17(6):1003-8.

16. Vasen AP, Kuntz KM, Simmons BP, Katz JN. Open versus endoscopic carpal tunnel release: a decision analysis. J Hand Surg Am 1999;24(5):1109-17.

17. Spinner M. The anterior interosseous-nerve syndrome, with special attention to its variations. J Bone Joint Surg Am 1970;52(1):84-94.
18. Schantz K, Riegels-Nielsen $P$. The anterior interosseous nerve syndrome. J Hand Surg Br 1992;17(5):510-2.

19. Özdemir O, Coşkunol E, Özalp T. Anterior interosseöz sinir sendromu: Olgu sunumu. Ege Tip Dergisi 2002;41(3):185-7.

20. Eser F, Keskin ED, Bodur $H$. Anterior interosseöz sinir sendromu: Olgu sunumu. Türk Fiz Tıp Rehab Derg 2008;54:30-2.

21. Olehnik WK, Manske PR, Szerzinski J. Median nerve compression in the proximal forearm. J Hand Surg Am 1994;19(1):121-6.

22. al-Qattan MM, Husband JB. Median nerve compression by the supracondylar process: a case report. J Hand Surg $\mathrm{Br}$ 1991;16(1):101-3.

23. Seyffarth $\mathrm{H}$. Primary myoses in the $\mathrm{M}$. pronator teres as cause of lesion of the N. medianus (the pronator syndrome). Acta Psychiatr Neurol Scand Suppl 1951;74:251-4. 